\title{
ECOS DA PEDAGOGIA CRÍTICA FREIREANA NAS PERSPECTIVAS CRÍTICAS EM EDUCAÇÃO LINGUÍSTICA DE LÍNGUA INGLESA
}

\author{
ECHOES OF FREIREAN CRITICAL PEDAGOGY IN THE PERSPECTIVES OF \\ CRITICAL ENGLISH LANGUAGE EDUCATION
}

\author{
Recebido: 13/10/2021 Aprovado: 24/11/2021 Publicado: 22/12/2021 \\ DOI: $10.18817 /$ rlj.v5i2.2671 \\ Ricardo Regis de Almeida ${ }^{1}$ \\ Orcid ID: https://orcid.org/0000-0001-9049-8401 \\ Barbra Sabota ${ }^{2}$ \\ Orcid ID: https://orcid.org/0000-0002-3100-259X
}

\begin{abstract}
Resumo: Tendo como principal objetivo problematizar os conceitos de diálogo, colaboração e empoderamento - todos caros à pedagogia crítica difundida por Freire na década de 1970 - e apontar possibilidades outras de atuação crítica, o presente artigo se trata de uma pesquisa bibliográfica (LIMA, MIOTO, 2007), organizada a partir das discussões teóricas mobilizadas na dissertação de Mestrado do primeiro autor (ALMEIDA, 2017), revisitadas à luz do cenário atual. O texto está organizado da seguinte maneira: iniciamos a conversa apresentando algumas limitações nos conceitos de diálogo, colaboração e empoderamento empenhados pela pedagogia crítica. Revisitamos esses conceitos partindo das discussões de Ellsworth (1989), Urzêda-Freitas (2012) e Contreras (2012). Trazemos, em seguida, as perspectivas críticas como possibilidades de atuação na educação linguística crítica em língua inglesa. Por fim, tecemos algumas considerações transitórias a respeito da multiplicidade de teorizações sobre as perspectivas críticas no bojo da Linguística Aplicada Crítica (LAC).
\end{abstract}

Palavras-chave: Perspectivas críticas. Educação linguística. Língua inglesa. Paulo Freire.

Abstract: This paper problematizes the concepts of dialogue, collaboration and empowerment presented in the critical pedagogy spread by Freire in the 1970's and points out other possibilities of acting critically. It is a bibliographic research (LIMA; MIOTO, 2007) and draws on the theoretical assumptions mobilized in the first author's master's thesis (ALMEIDA, 2017), revisited in the light of our current scenario. The text is organized as follows: we start the conversation by presenting some limitations in the concepts of dialogue, collaboration and empowerment defended by the critical pedagogy. Next, we revisit these concepts based on the theoretical discussions presented by Ellsworth (1989), Urzêda-Freitas (2012) and Contreras (2012). We then bring different critical perspectives as possibilities for acting in critical language education in English. Finally, we make some transitory considerations regarding the multiplicity of theorizations about the critical perspectives within the scope of Critical Applied Linguistics (CLA).

Keywords: Critical perspectives. Language education. English. Paulo Freire.

\section{Primeiras palavras}

1 Doutorando em Letras e Linguística pela Universidade Federal de Goiás (UFG), mestre em Educação, Linguagem e Tecnologias pela Universidade Estadual de Goiás (2017) e licenciado em Letras - Português/Inglês e suas respectivas Literaturas (2014) pela mesma instituição. Membro do grupo de pesquisa E-mail: ricardoregisalmeida@gmail.com

2 Doutora em Letras e Linguística pela Universidade Federal de Goiás, com estágio de pós-doutoramento pelo Programa de Pós Graduação em Linguística Aplicada da UnB. Docente do curso de Letras Português e Inglês e do Programa de Pós-Graduação Interdisciplinar em Educação, Linguagem e Tecnologias (PPG-IELT) da Universidade Estadual de Goiás (Unidade de Anápolis - Ciências Socioeconômicas e Humanas UnUCSEH/UEG). E-mail: barbrasabota@gmail.com 
Em setembro de 2021 celebramos o centenário do nascimento do educador Paulo Freire - patrono da educação brasileira - e do seu legado educacional-políticointelectual. Embora sua pessoa física já não esteja entre nós, suas palavras permanecem vivas em nós. Seus ensinamentos sobre educação como ato político, o reconhecimento do/a aprendiz como sujeito/a cognoscente e a luta por justiça social são alguns dos pilares de sua pedagogia crítica. Por se tratar de um educador cujas palavras e atitudes transcenderam a própria vida física, o seu engajamento na busca por uma educação pautada pela justiça social e de amplo acesso às classes subalternizadas não podem ser simplesmente ignoradas ou pensadas de modo estático neste estudo.

Nessa linha de pensamento, pensamos ser imprescindível rememorar que a pedagogia crítica de Freire não se restringe à década de 1970, momento em que publica uma de suas obras de maior relevância: Pedagogia do oprimido (2014a [1970]), fundantes de sua pedagogia crítica e progressista. O próprio autor entende a educação como processual e inesgotável ao ser humano, o que fica nítido para aqueles/as que percebem as incontáveis transformações em seu modo de pensar e de escrever sobre possibilidades de atuação política no mundo social ao longo de sua vida, muitas delas reconhecidas e revisitadas em Pedagogia da esperança: um reencontro com a Pedagogia do oprimido (2014b [1992]).

Dito isso, embora a proposta deste artigo seja problematizar os conceitos de diálogo, colaboração e empoderamento - todos caros à pedagogia crítica difundida por Freire - e apontar possibilidades outras de atuação crítica, enfatizamos os movimentos e as ressignificações ocorridas tanto na pedagogia e na escrita de Freire como nas reverberações de suas palavras na construção de nossas práxis, haja vista que ambos autor e autora nos afiliamos à linhas críticas de pesquisa dentro da Linguística Aplicada. Nosso olhar para Freire é prenhe de vida e um convite a revisitar as palavras e os exemplos de sua atuação política que, a nosso ver, não devem jamais se restringir a um único momento de sua existência.

Isso posto, faz-se mister evidenciar que a obra de Paulo Freire produz significados profundos na formação de professores/as de línguas ao entender a educação como ato político e que sua pedagogia contribui diretamente para que estudantes não sejam entendidos/as como repositórios de conteúdos, mas sim agentes responsáveis pela produção do conhecimento. No que tange ao ensino de 
língua inglesa, mais especificamente, a pedagogia crítica de Freire se apresenta como pontapé inicial para uma proposta que visa desconstruir o ensino do idioma como mero objeto de consumo, passando a encará-lo como processo de construção de sentidos a partir de realidades situadas.

O próprio patrono da educação brasileira, em An incredible conversation ${ }^{3}$ - em tradução livre, "Uma conversa incrível" (1996), faz uso da língua inglesa sem o compromisso de se aproximar dos ideais de falante nativo. Ao problematizar questões de tolerância, curiosidade, poder e língua/linguagem em sua entrevista, a própria enunciação de Freire soa como provocação/convocação para revisitarmos conceitos importantes no campo de ensino de línguas estrangeiras/adicionais, tais como: proficiência, sotaque, competência, dentre outros.

$\mathrm{Na}$ entrevista, Freire se apropria da língua para construir sentidos seus, mostrando o que ela pode adicionar ao enunciador e a quem o ouve, engajando pessoas de línguas outras em um processo de construção de sentidos. Para nós, postulando um convite a um inédito viável de se pensar a educação linguística. É nesta esteira que nos colocamos a pensar de que maneiras a pedagogia crítica de Freire e as perspectivas críticas em educação linguística mais atuais podem contribuir para a problematização e ressignificação desses ideais.

Feitos os apontamentos necessários, o presente artigo se trata de uma pesquisa bibliográfica (LIMA, MIOTO, 2007), organizada a partir das discussões teóricas mobilizadas na dissertação de Mestrado do primeiro autor (ALMEIDA, 2017) e revisitadas à luz do cenário atual. $O$ artigo está organizado da seguinte maneira: iniciamos a conversa apresentando algumas limitações nos conceitos de diálogo, colaboração e empoderamento empenhados pela pedagogia crítica. Revisitamos esses conceitos partindo das discussões de Ellsworth (1989), Urzêda-Freitas (2012) e Contreras (2012) e propomos algumas ressignificações sob o olhar atual a respeito deles. Trazemos, em seguida, as perspectivas críticas como possibilidades de atuação na educação linguística crítica em língua inglesa. Por fim, tecemos algumas considerações transitórias a respeito da multiplicidade de teorizações sobre as perspectivas críticas no bojo da Linguística Aplicada Crítica (LAC).

\section{Pedagogia crítica: mobilizando conceitos-chave}


Relembrar o papel da pedagogia crítica no ensino de línguas é certamente revisitar e aprender com a obra de Paulo Freire (2014a [1970]), um dos mais importantes pensadores dessa pedagogia no século $X X$. A sua experiência de vida fez com que ele mesmo experimentasse "a violência das oligarquias rurais remanescentes no nordeste brasileiro que tiram partido da ignorância do povo" (COX; ASSIS-PETERSON, 2001, p. 12) e passasse a enxergar na educação um meio possível de libertação dos seus sofrimentos, que também eram e ainda são os sofrimentos do povo.

Cox e Assis-Peterson (2001) assinalam que a pedagogia crítica tem um sentido profundo na obra de Paulo Freire, pois, por várias vezes, ele reforça que "a educação é um ato político e não encará-la como tal é permitir que ela sub-repticiamente legitime e reproduza a política das classes dominantes, perpetuando as desigualdades sociais" (p. 12). Nesse sentido, compreender a educação como ato político é assumir que os/as responsáveis por ela devem refletir e agir no e com o mundo em busca de transformações (FREIRE, 2014a [1970]). Nesta busca pela ação conjunta e da responsabilidade compartilhada no processo educativo, Freire ressalta a relevância de que o compromisso e o engajamento de educadores/as com a educação sejam genuínos e se comprometam com a justiça social de modo a mostrar que a "solidariedade ultrapassa os limites da curiosidade intelectual" e se põe ao lado dos/as que buscam reparação histórica e social de injustiças sócio- historicamente construídas e mantidas. (FREIRE, 2014b [1992], p. 99).

A esse respeito, a pedagogia crítica considera inconcebível uma proposta de educação como ato político que não se baseie em dois princípios básicos: no diálogo e na colaboração entre os/as responsáveis pelo processo de ensino-aprendizagem, o que remete ao que Freire (2014a [1970], p. 95) defende na obra Pedagogia do Oprimido: "ninguém educa ninguém, ninguém educa a si mesmo, os homens [sic] se educam entre si, mediatizados pelo mundo". Para o educador, o/a professor/a verdadeiramente dialógico/a e crítico/a será sempre sujeito/a cognoscente, na medida em que ele/ela está sempre em processo de des/re/aprendizagem, refazendo-se e reposicionando-se diante dos problemas com os quais ele/ela mesmo/a constrói ou se depara ao longo de sua trajetória. Além do mais, o educador parte do princípio de que é preciso refletir sobre o ato político de ensinar, extrapolandoa imagem distorcida 
de professores/as como transmissores/as de conhecimento, passando, assim, "a um mediatizador de sujeitos cognoscentes" (FREIRE, 2014a [1970], p. 94).

Ira Shor e Paulo Freire (2011 [1986]) discutem os significados de diálogo que atravessam a proposta da pedagogia crítica. Para Freire, o ponto de partida para acessar o significado de diálogo é não o compreender como mera técnica que objetiva somente resultados quantitativos no processo pedagógico. Visto dessa maneira, alertam os autores, esse conceito pode gerar interpretações vazias e maléficas que operam para fins de manutenção da educação bancária e da opressão das classes subalternizadas.

Contrários a essa noção, eles argumentam que o diálogo "deve ser entendido como algo que faz parte da própria natureza histórica dos seres humanos. É parte do nosso progresso histórico, do caminho para nos tornarmos seres humanos!" (SHOR; FREIRE, 2011 [1986], p. 167). Dessa maneira, o ato dialógico passa a enfatizar o momento de construção interpessoal, um encontro de subjetividades em que, ao refletirem sobre as suas realidades e se engajarem nesse processo, as pessoas assumem o papel de agentes capazes de refazer as suas práticas e as ressignificar. É um processo demorado, mas que se inicia com a atitude de assumir sua liberdade - de pensar, agir e ser dentro de seus contextos e auxiliar no projeto de reconfigurar realidades. Daí a relevância da busca por um diálogo libertador, o qual atesta a possibilidade dos/as seus/suas participantes de se recriarem e recriarem os seus contextos.

Ao pensar o diálogo no contexto educacional, Shor e Freire ressaltam como ele permite que educadores/as e alunos/as participem do processo educativo em conjunto, aprendendo e ensinando com e a partir de vivências coletivas, menos hierarquizadas e mais cientes da responsabilidade de cada um/a. Assim, o/a educador/a demonstra a sua capacidade profissional de conhecer o objeto, ao mesmo tempo em que se refaz, cada vez mais, por meio da capacidade dos/as alunos/as de também conhecerem e modificarem esse objeto. Essa agência conjunta entre educadores/as e educando/as coloca ambos em movimento na ampliação de saberes - acadêmicos e não acadêmicos - evidenciando que o saber se encontra em devir constante, pois como ressalta Freire (2014b [1992], p. 98 - grifos no original), "partir do 'saber de experiência feito' para superá-lo não é ficar nele”.

Ainda em sua conversa com Ira Shor, Freire (2011 [1986], p. 183) compartilha o seu medo de usar a palavra empoderamento sem uma reflexão mais profunda sobre 
o termo, pois, segundo ele, "algumas pessoas acham que essa prática ativa a potencialidade criativa dos/as alunos/as, e então está tudo terminado, nosso trabalho está arruinado, liquidado!". Visto sob essa ótica, ele afirma que o empoderamento pode parecer muito simples e arriscado para o trabalho do/a professor/a, o que não vem a ser o caso. Dessa maneira, o educador acredita que não há uma autolibertação do sujeito, sendo a libertação um ato social, uma vez que

mesmo quando você se sente, individualmente, mais livre, se esse sentimento não é um sentimento social, se você não é capaz de usar sua liberdade recente para ajudar os outros a se libertarem através da transformação global da sociedade, então você só está exercitando uma atitude individualista no sentido do empowerment ou da liberdade. (SHOR; FREIRE, 2011 [1986], p. 185).

Nesse sentido, ainda que alguns/algumas estudantes compreendam a relevância de se libertarem através de um deslocamento mais amplo e colaborativo, eles/elas acabam se esbarrando em barreiras impostas pela lógica neoliberal. Em outras palavras, embora a tomada de consciência crítica dos/as aprendizes sobre a sua realidade, a sua criatividade e a sua capacidade de intervir nesses contextos não sejam suficientes para mudanças nas estruturas sociais mais profundas, elas ainda se configuram como atitudes profundamente necessárias para o processo de libertação e de transformação social (SHOR; FREIRE, 2011). Empoderar, por conseguinte, na perspectiva da pedagogia crítica, implica uma atitude críticocolaborativa daqueles/as que buscam refletir sobre as suas realidades e alterar aquelas consideradas subalternas e marginais. De todo modo, acreditamos ser relevante indagar: de onde emerge essa matriz de poder? Quem empodera quem nesse processo? Seria o empoderamento uma prática realmente capaz de "libertar" as pessoas da opressão e da exclusão social?

Com base no exposto, corroboramos a opinião dos estudiosos a respeito da relevância do diálogo e da colaboração entre alunos/as e professores/as, haja vista que essa relação pode trazer benefícios reais para uma educação mais política, humanizada e menos desigual. Por outro lado, também acreditamos na relevância de problematizar as relações de poder que, apesar de não serem estanques ou estáticas, acabam por outorgar certos 'privilégios' aos/às professores/as, visto que estão inscritos/as em uma hierarquia de superioridade dentro da lógica institucional. 
Dito de outra forma, muitos/as educadores/as acabam monopolizando decisões que poderiam ser compartilhadas com os/as educandos/as horizontalizando mais as relações durante o processo de aprendizagem como: selecionar juntos/as temas e conteúdos que pautam as discussões em aula, debater processos e modos de avaliação formativa, compartilhar modos de ensinar e de aprender que coloquem em diálogo os saberes da palavramundo. Essas são algumas maneiras que trazemos como alternativa para o gerenciamento conjunto dos processos pedagógicos, como discutimos também em Sabota, Almeida e Moura (2021). Tais ações se configuram como esforços que viabilizam o giro necessário para combater e superar uma noção de conhecimento objetivista, cumulativa, linear e que pressupõe que docentes são os/as únicos/as a saber aquilo que é relevante para a formação do/a aprendiz.

Por isso e por tantos outros motivos não elencados aqui, atuar criticamente é um compromisso com a construção de uma possibilidade de educar para questionar e pensar modos outros de ser e estar no mundo social. Isso implica compreender a relevância de se reinventar e se reorganizar constantemente. Nessa vereda, defendemos que a discussão sobre diálogo e colaboração são profundamente pertinentes, porém não se encerra aqui. Ainda é preciso lançar luz às relações desiguais de poder que operam dentro e fora das instituições, sendo essas as responsáveis, na ampla maioria das vezes, por ditar quem empodera quem. $\mathrm{Na}$ tentativa de lançar inteligibilidade aos questionamentos sobre empoderamento e às possíveis lacunas sobre diálogo e colaboração, passamos agora para uma breve problematização desses conceitos.

\section{Movimentando sentidos de conceitos caros à pedagogia crítica}

Para Urzêda-Freitas (2012, p. 35), a pedagogia crítica fundamenta-se em quatro conceitos-chave: empoderamento, conscientização, democracia e diálogo. Entretanto, como opróprio autor pondera, "ao contrário do que possamos pensar em um primeiro momento, a pedagogia crítica não se realiza fora do conflito e nem está isenta de contradições". Nessa perspectiva, Ellsworth (1989) é mencionada pelo pesquisador como uma das teóricas que questiona as noções de empoderamento e diálogo presentes nas teorias pedagógicas críticas. Isso porque tais conceitos e até mesmo a noção de crítica, conforme entendidos pela pedagogia crítica, são para Ellsworth (1989, p. 298), "mitos repressivos que perpetuam relações de dominação". 
A autora chega a essa conclusão revivendo uma experiência de seu curso Pedagogias Midiáticas e Antirracistas, ofertado em resposta aos atos preconceituosos e racistas dos/as próprios/as alunos/as que ocorriam no interior do câmpus e ao racismo institucional presente tanto no currículo da universidade como na pedagogia dos/as professores/as. Segundo ela, o curso também tinha como propósito planejar e proporcionar uma ação política dos/as aprendizes no interior daquela formação.

Contudo, Ellsworth (1989) afirma que quando os/as alunos/as matriculados/as no curso tentaram aplicar as prescrições (prescriptions) oferecidas na literatura especializada sobre pedagogia crítica, eles/elas (a autora e os/as discentes) não só produziram resultados incompatíveis com aqueles esperados, como também reforçaram os princípios das práticas às quais se diziam contrários/as, "inclusive o eurocentrismo, o racismo, o sexismo, o classismo e a 'educação bancária4"' (ELLSWORTH, 1989, p. 298, grifo no original).

A autora segue argumentando que a pedagogia crítica sugere ser capaz de libertar os/as excluídos/as e oprimidos/as a partir de pressupostos racionalistas:

\footnotetext{
[As] reivindicações feitas em documentos, protestos, coletivas de imprensa e em discussões em sala de aula entre estudantes negros/as e estudantes brancos/as contra o racismo poderiam ser legitimamente empregadas em sala de aula e sujeitas à deliberação racional de suas verdades à luz de reivindicações concorrentes (ELLSWORTH, 1989, p. 305).
}

Como sinaliza a estudiosa, para alcançar tais objetivos seria necessário que os/as alunos/as se submetessem às lógicas do racionalismo e do cientificismo, as quais só são possíveis "através da exclusão de Outros/as que foram socialmente construídos/as como irracionais - mulheres, negros/as, natureza e estética" (ELLSWORTH, 1989, p. 305). Nesse sentido, as teorias críticas nos fazem acreditar na possibilidade de identificarmos racionalmente as contradições presentes nas práticas docentes e discentes, tornando possível a teorização e superação destas a partir de um processo de reflexão crítica (CONTRERAS, 2012, p. 196).

No que concerne ao papel do/a educador/a crítico/a, Ellsworth (1989) ressalta que a pedagogia crítica 'avançou' no sentido de reconhecer a autoridade exercida por esse/essa profissional sobre os/as alunos/as. Contudo, ela entende que os/as teóricos/as defensores de tal pedagogia ainda não possuem qualquer análise 
significativa voltada para a redistribuição do poder institucionalmente concedido aos/às professores/as. A autora argumenta, então, que na ausência de uma agenda explícita para problematizar tal questão, esses/as teóricos/as limitam seus estudos à tentativa de transformar a distribuição desigual de poder dentro da sala de aula em aspectos positivos.

Duas estratégias para ocultar essas relações assimétricas de poder em sala de aula são, de acordo com Ellsworth (1989, p. 306), a noção de empoderamento do/a aluno/a e a noção de diálogo, que, na pedagogia crítica, "dão a ilusão de igualdade enquanto, de fato, deixa a natureza autoritária da relação professor(a)/aluno(a) intacta". Todavia, a autoridade concedida aos/às docentes já é suficiente para entendermos que a distribuição de poder em sala de aula será sempre desigual, uma vez que o papel institucionalmente outorgado aos/às professores/as lhes garante uma maior visibilidade e aceitação das suas opiniões do que das opiniões do alunado (ELLSWORTH, 1989).

Outro apontamento feito por Ellsworth (1989) refere-se à tentativa da pedagogia crítica de fazer com que o/a professor/a também se veja e exerça mais o papel de aprendiz em suas aulas. Em alusão à obra de Ira Shor e Paulo Freire, a estudiosa aponta que os autores sugerem que o/a docente inicia qualquer processo de ensino ou de seleção de materiais sabendo mais que os/as alunos/as, porém, ao longo desse processo, reformula seus conhecimentos a partir dos saberes de seus/suas discentes. Para a autora, o único motivo pelo qual isso ocorre tem a ver com a possibilidade de "habilitar o/a professor/a para traçar estratégias mais eficazes de elevar o/a aluno/a ao nível de compreensão do/a professor/a", o que revela os objetivos de uma formação que oferece receitas aos/às aprendizes para que se tornem "tão livres, racionais e objetivos quanto os/as seus/suas professores/as supostamente são para escolher posições sobreos seus objetivos" (ELLSWORTH, 1989, p. 306).

A estudiosa assinala que nem sempre o conhecimento que o/a professor/a traz consigo para a sala de aula é, de fato, mais elaborado ou superior ao conhecimento dos/as alunos/as. Como exemplo, temos a própria experiência da autora que, ao elaborar um curso que tinha por intenção problematizar o racismo presente nas práticas dos docentes e discentes de sua universidade, percebeu não estar mais preparada do que os/as seus/suas alunos/as para discutir a questão do racismo, "especialmente aqueles/aquelas alunos/as negros/as que vão para as aulas depois de seis meses (ou mais) de ativismo no câmpus e que têm uma vida inteira de 
experiência e de luta contra o racismo" (ELLSWORTH, 1989, p. 308). Para ela, outros fatores como a sua pele branca, o seu corpo fisicamente apto (able-bodied) e magro, e a sua carreira como professora universitária e de classe média não a permitiram atuar em favor dos/as seus/suas alunos/nas na busca por encontrar suas vozes como cidadãos/cidadãs negros/as. Assim, finaliza:

\begin{abstract}
A minha compreensão e experiência sobre o racismo será sempre restrita devido à minha pele branca e ao meu privilégio de ser de classe média. $\mathrm{Na}$ verdade, é impossível que qualquer pessoa esteja livre dessas formações opressivas neste momento da história. Além do mais, embora eu esteja munida do poder institucional e da autoridade dentro da sala de aula para aplicar uma "prática reflexiva" acerca da pluralidade de posições políticas e morais diante de nós de um modo que os meus julgamentos supostamente parecem possuir o mesmo peso que os dos/as meus/minhas alunos/as, de fato, o meu próprio papel institucional como professora já faz com que as minhas afirmações sejam sempre ponderadas de forma diferente das dos/as meus/minhas alunos/as (ELLSWORTH, 1989, p. 308, grifo meu).
\end{abstract}

Desse modo, o que é possível de se extrair da experiência de Ellsworth com a pedagogia crítica é que independentemente do engajamento dos/as professores com a transformação social e com o empoderamento dos/as seus/suas alunos/as, a distribuição de poder em sala de aula entre docente e discente e o lugar de onde cada um/uma fala serão sempre desiguais (ELLSWORTH, 1989). Nessa perspectiva, a autora alega que o diálogo passa a ser inconcebível conforme entendido na pedagogia crítica, uma vez que as categorias de gênero, classe social e raça podem não ser as mesmas compartilhadas pelos/as professores/as ealunos/as, evidenciando, mais uma vez, as relações de poder assimétricas e injustas entre eles/as são evidenciadas e colocadas em xeque.

Embora seja distópico pensar em um cenário desprovido de relações de poder e atravessamentos socio-identitários, é possível - e necessário, a nosso ver trabalhar a sala de aula e os ambientes escolares para que sejam mais inclusivos e favoreçam as relações de respeito e alteridade. Essas relações se tornam possíveis quando entendemos que no processo educativo é importante reconhecer no outro um sujeito de direitos e de saberes.

Apesar de Ellsworth apresentar reflexões um tanto céticas, há muito a ser considerado de sua experiência com os pressupostos da pedagogia crítica. Exemplo disso é a advertência feita por Contreras (2012), sustentada nos estudos de Ellsworth (1989), contra o julgamento que fazemos de outras pessoas com base em nossas 
perspectivas teóricas, "como se fosse possível extrair uma compreensão de experiências humanas e vitais da perspectiva de um sujeito cognoscente que não está vivendo tais circunstâncias" (CONTRERAS, 2012, p. 199).

Esse apontamento foi o responsável por nos auxiliar a perceber, a exemplo de Urzêda-Freitas (2012), que nós, profissionais docentes, "devemos assumir que todo tipo de conhecimento, por mais crítico e emancipatório que possa ou pareça ser, é sempre parcial e interessado, podendo ser amplamente opressivo a outras pessoas" (URZÊDA-FREITAS, 2012, p. 36). Tal constatação amplia nossa responsabilidade como educadores/as críticos/as de desconstruir barreiras que impeçam os saberes de emergirem, pois é na vivência com o conflito e com o contraditório que aprendemos a conviver.

Conforme afirma Contreras (2012), ainda haverá espaço para reivindicarmos a liberdade e a igualdade, a justiça e a solidariedade, a compaixão e a alteridade em nossas práticas se, concomitantemente, os significados desses valores não forem unificados e essencializados, mas problematizados e negociados. Nesse viés, concordamos que os significados desses valores não podem ser entendidos como pré-concebidos e estáticos, mas construídos e reconstruídos nos espaços em que a diferença existe e é respeitada, contribuindo, assim, para posicionamentos contrários a qualquer prática de opressão, sofrimento, exclusão, silenciamento e de dor, o que pode parecer uma utopia aos olhos de quem lê, mas são atitudes que consideramos imprescindíveis aos/às que pautam suas práticas de educação linguística nas perspectivas críticas. É com base em tais pressupostos que apresentamos as potencialidades e os desafios das perspectivas críticas frente a esse desafio de encarar a educação linguística como espaço de escuta, problematizações e de mudança social.

\section{As perspectivas críticas como possibilidade de reivindicação e reinvenção do mundo social}

A pluralidade de perspectivas críticas no bojo de estudos inscritos na Linguística Aplicada Crítica visa movimentar os saberes sem alinhamentos exclusivos a vertentes teórico-acadêmicas específicas. É na intenção de construir uma educação linguística de caráter político, ético, social, problematizador, incerto, movente e transgressor, além de preocupada em abordar questões de desigualdade, poder, 
preconceito, raça, racismo, etnia, sexo, sexualidade, identidade, diferença, diversidade cultural, silenciamento, opressão, cidadania etc., que situamos os nossos esforços.

As perspectivas críticas buscam problematizar e reinventar as concepções hegemônicas de três conceitos base: sociedade, escola e ensino (BORELLI;PESSOA, 2011). Embora a pedagogia crítica também questione tais pressupostos, essa frente epistemológica parece fazer isso sempre em busca de uma possível 'verdade' que se esconde nos textos e abrigam ideologias perversas.

Além de lutar por ideais como os de emancipação, de justiça social, de conscientização e de igualdade social, a pedagogia crítica da década de 1970 também tinha como enfoque principal as condições de produção do texto, ou seja, quem o escreveu e em quais condições, para então mostrar ao/à leitor/a: "veja como essa pessoa quer que você compreenda esse texto de um determinado jeito, mas na verdade esse texto é outro, você precisa ler esse texto de uma forma verdadeira" (MENEZES DE SOUZA, 2011, p. 290-291).

Sendo assim, corroboramos a afirmação de Jordão (2013) de que a pedagogia crítica, o letramento crítico ou, ainda, o ensino crítico de línguas não são teorias que possam ser tomadas em sinonímia como "farinhas do mesmo saco". Contudo, essas perspectivas, cada uma a seu modo, podem nos auxiliar na construção e na problematização de nossos materiais empíricos, bem como podem permitir avaliar e reinventar conceitos já existentes nessas propostas críticas. Portanto, não basta assumirmos o compromisso pela construção e uso de teoria(s), seja(m) ela(s) crítica(s) ou não, mas sim o comprometimento desta(s) em transformar o pensamento dominante (PESSOA; BORELLI, 2011), que, a nosso ver, é papel central de todas as perspectivas críticas.

Com base em tal proposta, Pessoa e Borelli (2011) advogam que o diálogo e a colaboração entre os/as professores/as se configura como possibilidade de reflexão crítica e de transformação de práticas hegemônicas que embasam atitudes dentro e fora da sala de aula, na medida em que "cabe aos/às próprios/as professores/as teorizar sobre o processo de construção de conhecimento em sala de aula e encontrar maneiras de ensinar que sejam pautadas pelo contexto e que acarretem resultados positivos para a aprendizagem de todos/as os/as alunos/as" (PESSOA; BORELLI, 2011, p. 59).

Segundo as estudiosas, é no momento em que esses/essas profissionais se 
reúnem e passam a desenvolver uma escuta sensível para ouvir dos/as seus/suas colegas de trabalho as suas experiências que lhes é permitido problematizar as suas práticas e, assim, perceber que outras realidades existem e são experimentadas por outras pessoas, sejam alunos/as ou não. Assim, a/o docente que busca refletir criticamente não deve encarar esse processo como individual, estanque, sólido e com definições únicas e seguras; pelo contrário, ele/ela deve se pautar em propostas pensadas colaborativamente e que aceitem a incompletude, a liquidez e as contrariedades de suas práticas e voltar-se para o reconhecimento e respeito das diferenças (PESSOA; BORELLI, 2011).

Nessa mesma linha de raciocínio, hooks ${ }^{5}$ (2013 [1994], p. 173) considera crucial que os/as professores/as dispostos/as a mudar suas práticas de ensino "conversem entre si, colaborem com uma discussão que transponha fronteiras e crie um espaço para a intervenção". A estudiosa, que alega ter sido profundamente tocada pela pedagogia de Paulo Freire, propõe uma pedagogia engajada que acredita no diálogo como um dos meios mais simples e poderosos para que professores/as e pensadores/as críticos/as possam "cruzar as fronteiras, as barreiras que podem ser ou não erguidas pela raça, pelo gênero, pela classe social, pela reputação profissional e por um sem-número de outras diferenças" (hooks, 2013 [1994], p.174).

A autora expõe que o primeiro paradigma responsável por moldar as suas práticas pedagógicas foi "a ideia de que a sala de aula deve ser um lugar de entusiasmo, nunca de tédio" (hooks, 2013 [1994], p. 16). Todavia, o entusiasmo gerado pela ideia de sala de aula como espaço de prazer sem o agenciamento de todos/as os/as responsáveis pelo processo de aprendizagem não é capaz de promover mudanças ou de proporcionar o que a estudiosa chama de "processo de aprendizagem empolgante". Para que a proposta se concretize, é necessário que todos/as se sintam afetados/as pela presença uns/umas dos/as outros/as e se interessem por ouvir as suas histórias de vida e aprender com elas. Por isso ela considera crucial que os/asprofessores/as dispostos/as a mudar as suas práticas de ensino tenham o hábito de conversar entre si e com os/as seus/suas discentes para que juntos/as possam compreender as limitações de suas práticas e propor alternativas que rompam essas barreiras e criem um espaço propício para novas

5 Mantemos o nome da autora com iniciais minúsculas, tal como ela o assina por respeito à transgressão marcada em sua prática na intenção de evidenciar que os seus escritos em si são mais importantes do que a pessoa que os escreveu. 
ações interventivas (hooks, 2013 [1994]).

A estudiosa entende ainda que é preciso estimar o valor e a singularidade de cada um/uma e das suas experiências e permitir que todos/as compartilhem as suas vivências sem que alguns/algumas tenham as suas vozes privilegiadas ou silenciadas. Ademais, é essa atitude que contribui para a criação de uma consciência coletiva acerca da diversidade presente nas experiências, o que implica em uma possível conscientização sobre o modo como nós pensamos, dizemos e agimos. A sala de aula vista sob tal ótica é transformada, então, em um "espaço onde a experiência é valorizada, não negada nem considerada sem significado" (hooks, 2013 [1994], p. 114-115).

Urzêda-Freitas (2012, p. 56), por sua vez, nos relembra que o ensino crítico de LE/LA inglês se origina das teorizações pedagógicas da LAC, proposta por Alastair Pennycook (2001), as quais "apontam para uma relação entre o ensino de línguas e o mundo/a realidade social". Com base em tal afirmação, Pessoa e Urzêda-Freitas (2012a, p. 1) entendem que educação e justiça social devem andar juntas, ao passo que, "professores/as não devem apenas ensinar os conteúdos de uma dada matéria, mas também encorajar os/as seus/suas alunos/as a pensarem criticamente para que eles/elas possam estar cientes da opressão e aprendam a lutar contra ela27". Entretanto, como a autora e o autor salientam, para que seja possível combater a opressão, é necessário que os/as professores/as também reconheçam e observem como as relações de poder operam em suas profissões e em suas vidas de modo geral para que possam dirimi-las, sempre que tais relações flertem com a injustiça ou escapem das relações de equidade e respeito.

Pessoa e Urzêda-Freitas (2012a) também buscam tornar o ensino de línguas, em especial o de LE/LA, uma atividade mais política. Ambos afirmam que, se considerarmos que as pessoas usam a língua para interagir umas com as outras, será possível pensar que esse uso pode ter diferentes propósitos, na medida em que "todas as pessoas tendem a usar a lingua[gem] consciente ou inconscientemente ou para difundir alienação, reforçando o preconceito e a discriminação ou, inversamente, para explorar as palavras em seus repertórios linguísticos com o propósito de lutar por justiça e liberdade" (PESSOA; URZÊDA-FREITAS, 2012a, p. 2).

Pessoa e Urzêda-Freitas (2012b) entendem ainda que o domínio crítico em sala de aula está no exercício de constante problematização da realidade por meio da língua e dos nossos corpos. No entanto, a autora e o autor nos chamam a atenção 
para o fato de que "a problematização do ensino de línguas se concretiza não apenas nas provocações feitas pelo/a professor/a, mas também nas atividades que desafiam os/as alunos/as a pensar como se pode agir de forma diferente e, assim, vislumbrar possibilidades de mudança" (PESSOA; URZÊDA-FREITAS, 2012b, p. 60).

Desse modo, o/a professor/a deve considerar as leituras que seus/suas alunos/as fazem do mundo por meio da lingua[gem], pois é a partir dessas interpretações que eles/elas definem, ao mesmo tempo que permitem ao/à docente também definir, "a realidade social da sala de aula, da escola, do mundo e, não com menos importância, delinear suas subjetividades" (PESSOA; URZÊDAFREITAS, 2012b, p. 60). Ademais, é preciso enfatizar a agência do/a aprendiz nesse processo de leitura, pois, como afirma Menezes de Souza (2011, p. 290):

\begin{abstract}
Ele não é mais somente aquele ser que recebe - os nossos aprendizes são agentes, fazedores. E como isso nos afeta na sala de aula, na construção do conhecimento? O aprendiz é independente, ele busca, seleciona, aprende, interage. Isso são coisas que devem permear as nossas maneiras de agir na sala de aula.
\end{abstract}

Depreende-se, então, que os/as aprendizes engajados/as em um trabalho crítico deveriam recusar-se a agir como recipientes onde um saber pronto e acabado seria depositado e assumirem-se sujeitos/as produtores/as de um conhecimento significativo, contingente e coerente com as suas práticas sociais e que se faça transgressor, quando necessário. Nesse sentido, Okazaki (2005, p. 181) nos permite compreender que:

[a] despeito de o conteúdo ser acadêmico ou não, a conscientização por meio de temas críticos requer um nível profundo de engajamento de ambos/as os/as alunos/as e professor/a. É crucial que o conteúdo seja imediato e significativo para os/as aprendizes, tornando-os/as, desse modo, conscientes da sua natureza reprodutiva e da possibilidade de resistência aos conteúdos problemáticos.

Assim, como o próprio autor afirma, é necessário que professor/a e alunos/as estejam profundamente envolvidos/as com os temas discutidos em sala para que estes possam ser de fato problematizados e não pretextos ou alegorias em aulas de idiomas. Problematizar os temas se opõe a tematizar as aulas uma vez que passa a mobilizá-los como conteúdos que permitam a todos/as "o questionamento das práticas discursivas que bloqueiam a voz das minorias, dos/as diferentes" (PESSOA; URZÊDA-FREITAS, 2012b, p. 60). 
Okazaki (2005) alega ainda que a discussão de temas críticos deve ser significativa e instigante para todos/as os/as participantes do processo educativo, pois requer tanto do/a professor/a como dos/as alunos/as um nível de comprometimento mais profundo com as suas crenças, experiências e desejos. Desse modo, ele assevera que a problematização de temas críticos próximos das vivências e realidades dos/as alunos/as permite que eles/elas também desenvolvam as suas competências escrita, gramatical e oral. Além disso, a partir do momentoque o/a docente participa do processo de aprendizagem juntamente com os/as seus/suas alunos/as, ele/ela lhes mostra "como o conhecimento é construído e compartilhado pelo grupo através do diálogo" (OKAZAKI, 2005, p. 177). Uma vez produtores/as dos seus saberes e nãomeros/as consumidores/as, os/as aprendizes assumem um papel de agência e passam a problematizar as formas hegemônicas de produção do conhecimento e a buscar caminhos para resisti-las ${ }^{30}$ (OKAZAKI, 2005).

A compreensão de que o conhecimento é parcial e inacabado, conforme apontado anteriormente, nos leva a refletir sobre a multiplicidade de sentidos possibilitada pela diversidade de saberes presentes na sociedade, o que, na perspectiva do Letramento Crítico deve ser visto como algo produtivo (JORDÃO, 2014). Nesse esteio, a autora afirma que não existe uma única realidade ocultada por ideologias nocivas, conforme entendido pela pedagogia crítica; pelo contrário, o que existe são verdades construídas ideologicamente e disseminadas no meio social através do discurso. Assim, o que vai caracterizar essas verdades - levando a julgálas como melhores ou piores, superiores ou inferiores, maléficas ou benéficas em relação às outras dependerá do acionamento de sistemas de valores específicos, de determinadas crenças, de visões de mundoparticulares e de processos interpretativos definidos (JORDÃO, 2014), por isso é premente fortalecer o trabalho com a edificação da ética, da política e da crítica em seus sentidos ontoepistêmicos.

Já o papel do/a professor/a nessa perspectiva passa a ser o de perceber essa multiplicidade de sentidos como fator positivo e auxiliar os/as seus/suas alunos/as a construir significados novos para suas práticas "a partir das diferentes possibilidades que se lhe apresentam no mundo, dentro e fora da sala de aula" (JORDÃO, 2013, p. 76). Desse modo, ela argumenta que no Letramento Crítico, nem o/a professor/a nem os/as alunos/as são detentores/as da verdade, conhecedores/as do mundo ou donos do conhecimento. Contudo, a autora assevera que alguns/algumas terão seus argumentos mais aceitos do que outros/as em razão da existência de um processo 
cultural responsável por hierarquizar sentidos e processos interpretativos, o que não deve ser confundido com aexistência de uma verdade universal ou supostamente intrínseca aos fenômenos que ocorrem no/com o mundo e nas/com as pessoas. A "verdade", por conseguinte, "existe concretamente nas práticas sociais, e não etereamente como atributo inerente a determinados conhecimentos ou formas de conhecer" (JORDÃO, 2013, p. 76-77). Isso equivale dizer que tanto na formação docente quanto na educação linguística em diversos níveis de escolarizaçao é pertinente questionarmos como essas verdades são construídas e mantidas sóciohistoricamente.

\section{Considerações transitórias}

O presente artigo teve por objetivo problematizar os conceitos de diálogo, colaboração e empoderamento inseridos na pedagogia crítica e apontar outras possibilidades de atuação crítica, principalmente a partir das diferentes perspectivas críticas presentes na seara da Linguística Aplicada Crítica. Feitas as devidas ressalvas a respeito de possíveis (des)encontros entre as perspectivas críticas abordadas, propomos o seguinte questionamento inspirados em Silvestre (2014): afinal, existiria uma única abordagem crítica e genuína de ensinar e aprender Língua Estrangeira / Língua Adicional?

Assim como compreende a estudiosa, argumentamos que não, pois, conforme apresentamos no decorrer do artigo, o que existem são "diferentes perspectivas críticas de trabalho no contexto atual de educação linguística" (SILVESTRE, 2014, p. 70). Portanto, o que há é uma pluralidade de perspectivascríticas que, cada qual a sua maneira, pode contribuir para a criação de uma agenda responsável, problematizadora, autorreflexiva e, principalmente, atuante na elaboração de possibilidades menos desiguais de ser e agir no mundo social.

No caso da educação linguística crítica em aulas de inglês, as teorizações presentes nas perspectivas críticas demonstram que ações políticas dos/as agentes envolvidos/as nesse processo não devem se restringir à aquisição das habilidades de leitura, escrita, compreensão auditiva e produção oral. Nossa premissa é de que como prática social a língua(gem) é entendida e co-criada a partir de diferentes dimensões (políticas, sociais, históricas, culturais, econômicas) e não apenas sistêmicas e estruturais. Os atravessamentos que compõem os contextos de uso, produção e 
compreensão de línguas estrangeiras/adicionais não devem ser alijados no processo, o que levaria a priorizar os padrões que intentam copiar a falácia do falante nativo e suas características idealizadas, por exemplo.

Por fim, as perspectivas críticas apresentadas neste artigo apontam para uma atuação política que questiona as normas raciais, sociais, de classe, gênero, sexualidade religião e linguísticas, e busca a criação de um mundo em que a boniteza do esperançar (FREIRE, 2014b [1992]) seja motivo suficiente para a existência de menos desigualdade e injustiça social entre nós. Seguimos firmes na construção de diálogos em que uma educação linguística outra favoreça e fortaleça relações de respeito e alteridade que acolham inéditos viáveis e promovam incredible conversations como as de Paulo Freire conosco.

\section{Referências}

ALMEIDA, R. R. de. Educação Linguística Crítica de Aprendizes de Inglês: problematizações e desestabilizações. 2017. 145f. Dissertação (Mestrado em Educação Linguagem e Tecnologias) - Universidade Estadual de Goiás, Anápolis, 2017.

BORELLI, J. D. V. P.; PESSOA, R. R. Linguística aplicada e formação de professores: convergências da atuação crítica. In: BORELLI, J. D. V. P.; PESSOA, R. R. (org.). Reflexão e crítica na formação do professor de língua estrangeira. Goiânia: Editora UFG, 2011, p. 15-30.

CONTRERAS, J. A autonomia de professores. São Paulo: Cortez, 2012 [1999].

COX, M. I. P.; ASSIS-PETERSON, A. A. O professor de inglês entre a alienação e a emancipação. Revista Linguagem \& Ensino, v. 4, n. 1, p. 11-36, 2001.

ELLSWORTH, E. Why doesn't this feel empowering? Working through the repressive myths of critical pedagogy. In: LUKE, C.; GORE, H. (org.) Feminisms and critical pedagogy. New York: Routledge, 1989, p. 297-324.

FREIRE, P. Pedagogia do Oprimido. Rio de Janeiro: Paz e Terra, 2014a [1970].

FREIRE, Paulo. Pedagogia da esperança: um reencontro com a pedagogia do oprimido. Editora Paz e Terra, 2014b [1992].

hooks, B. Ensinando a transgredir: a educação como prática da liberdade. São Paulo: WMF Martins Fontes, 2013 [1994].

JORDÃO, C. M. Abordagem comunicativa, pedagogia crítica e letramento crítico farinhas do mesmo saco? In: ROCHA, C. H.; MACIEL, R. F. Língua estrangeira e 
formação cidadã: por entre discursos e práticas. Campinas, SP: Pontes Editores, 2013, p. 69-90.

JORDÃO, C. M. Birds of different feathers: algumas diferenças entre letramento crítico, pedagogia crítica e abordagem comunicativa. In: TAKAKI, N. H.; MACIEL, R. F. (org.). Novos letramentos em terra de Paulo Freire. 1ed. São Paulo: Pontes, 2014, v.1, p. 195-207.

LIMA, T. C. S.; MIOTO, R. C. T. Procedimentos metodológicos na construção do conhecimento científico: a pesquisa bibliográfica. Revista Katálysis, v. 10, p. 37-45, 2007.

MENEZES DE SOUZA, L. M. T. O professor de inglês e os letramentos no século XXI: métodos ou ética? In: JORDÃO et al. (org.). Formação "desformatada" práticas com professores de língua inglesa. Campinas, SP: Pontes, 2011, p. 279-303.

OKAZAKI, T. Critical consciousness and critical language teaching. Second language studies, v.23, n. 2, 2005, p. 174-202.

PENNYCOOK. A. Critical Applied Linguistics: a critical introduction. Mahwah, NJ: Lawrence Erlbaum Associates, 2001.

PESSOA, R. R.; BORELLI, J. D. V. P. Reflexão crítica e colaborativa na formação do professor de língua estrangeira. In: BORELLI, J. D. V. P.; PESSOA, R. R. (org.). Reflexão e crítica na formação do professor de língua estrangeira. Goiânia: Editora UFG, 2011, p. 59-80.

PESSOA, R. R.; URZÊDA-FREITAS, M. T. Challenges in critical language teaching. Tesol Quarterly, v. 46, n. 4, 2012a, p. 753-776.

PESSOA, R. R.; URZÊDA-FREITAS, M. T. Ensino crítico de línguas estrangeiras. In: Francisco José Quaresma de Figueiredo. (org.). Formação de Professores de Línguas Estrangeiras: princípios e práticas. 1ed.Goiânia-GO: Editora da UFG, 2012b, v. 1, p. 57-80.

RAJAGOPALAN, K. Por uma linguística crítica: linguagem, identidade e a questão ética. São Paulo: Parábola Editorial, 2003.

SABOTA, B.; ALMEIDA, R. R. de.; MOURA, R. M. de. Retorno à sombra de uma mangueira: uma conversa sobre nossas praxiologias à moda de Paulo Feire. Filosofia e Educação, Campinas, SP, v. 13, n. 2, p. 2212-2234, 2021.

SHOR, I.; FREIRE, P. Medo e ousadia: o cotidiano do professor. Rio de Janeiro: Paz e Terra, 2011 [1986].

SILVESTRE, V. P. V. Ensinar e aprender língua estrangeira/adicional na escola: a relação entre perspectivas críticas e uma experiência prática localizada. $R B L A$, Belo Horizonte, v. 15, n. 1, 2014, p. 61-84. 
URZÊDA-FREITAS, M. T. "Pedagogia como transgressão": problematizando a experiência de professores/as de inglês com o ensino crítico de línguas. Dissertação (Mestrado em Letras e Linguística: Estudos Linguísticos). Faculdade de Letras, Universidade Federal de Goiás, 2012.

URZÊDA-FREITAS, M. T.; PESSOA, R. R. Discursos de identidades, ensino crítico de línguas e mudança social: análise de uma experiência localizada. In: MATEUS, E.; OLIVEIRA, N. B. (orgs.). Estudos Críticos da Linguagem e Formação de Professores/as de Línguas: Contribuições Teórico-Metodológicas. Campinas, SP: Pontes Editores, 2014, p. 365-395. 